\title{
POLÍTICAS FISCAL E MONETÁRIA E SUAS RELAÇÕES COM POBREZA DESIGUALDADE: REFLEXÕES SOBRE UM TEMA SEMPRE ATUAL
}

Frederico G. Jayme Jr

Julio César dos Reis

Ana Maria Hermeto Camilo de Oliveira

ABSTRACT | This paper aims to insert the discussion on poverty and income inequality in the context of macroeconomic policy represented here by fiscal and monetary policies. Therefore, we consider the reduction of poverty rate and the decrease of the income inequality index as the main objectives to be defined in the formulation and implementation of public policies. In this sense, a change of direction must be observed: instead of restrictive macroeconomic policies, with extreme concern in fighting inflation and generating fiscal surpluses, the macroeconomic policies proposed here are characterized by the promotion of continuous, sustained and balanced economic growth, and the distribution of its benefits.

KEY WORDS | Fiscal Policy, Monetary Policy, Poverty, Income Inequality

RESUMO | Este trabalho tem como objetivo inserir a discussão sobre a pobreza e a desigualdade de renda no âmbito da política macroeconômica - representada aqui pelas políticas monetária e fiscal. Para tanto, considera-se a diminuição da taxa de pobreza e a queda no índice de desigualdade de renda como objetivos centrais a serem definidos na formulação e implementação das políticas públicas. Nesse sentido uma mudança de orientação deve ser observada: ao invés de políticas macroeconômicas restritivas, com excessiva preocupação em combater a inflação e gerar superávits fiscais as políticas macroeconômicas aqui propostas são caracterizadas pela promoção do crescimento econômico contínuo, sustentado e equilibrado e pela distribuição dos frutos desse crescimento.

PALAVRAS-ChaVe | Política Fiscal, Política Monetária, Pobreza, Desigualdade de Renda 



\section{INTRODUC̣ÃO}

Há uma direta relação entre instrumentos de política econômica, combate à pobreza e melhoria do perfil distributivo da renda, não obstante a diversidade teórica de análise deste ponto seja significativa. As transformações sofridas em escala global, caracterizadas, grosso modo, por uma crescente integração, e os objetivos econômicos gerais de certa forma comuns - crescimento econômico, emprego, estabilidade de preços - ajudam a explicar essa relativa uniformidade em termos de política econômica.

O presente trabalho parte do princípio de que a dicotomia entre políticas focalizadas e políticas universais de combate à pobreza e melhoria na distribuição de renda não ajuda a avançar no tema. Aqui se pretende demonstrar analiticamente a importância de políticas macroeconômicas como protagonistas na relação entre pobreza, distribuição e bem-estar. Não obstante políticas focalizadas voltadas para redução da pobreza e melhoria no perfil distributivo tenham evidentes resultados, como o Programa Bolsa Família ou a política de valorização do salário mínimo, a negligência a uma política macroeconômica, tanto fiscal como monetária, voltada para o pleno-emprego pode conduzir a resultados pouco efetivos sobre o bem-estar.

Entendendo que o papel desempenhado pelos agentes econômicos determina os processos que constituem o sistema econômico, assim como condiciona o seu comportamento ao longo do tempo, e considerando que dentre esses agentes o Estado apresenta características singulares e possui instrumentos capazes de determinar o comportamento dos demais agentes, discutir o papel desempenhado pelo Estado, assim como analisar seus instrumentos políticos, é fundamental para se compreender a trajetória da economia.

O presente trabalho tem como objetivo discutir a conformação de políticas fiscais e monetárias no combate à pobreza e a melhoria na distribuição da renda. Para tanto, além dessa introdução, 
a seção dois discute a relação entre política fiscal e seus impactos em relação à pobreza, ao passo que a seção três se incumbe de discutir política monetária e seus impactos sobre a pobreza e distribuição. Uma última seção é destinada às considerações finais.

\section{POLÍTICAS MACROECONÔMICAS, COMBATE À POBREZA E A MELHORIA DA DISTRIBUIC̣ÃO DE RENDA: A POLÍTICA FISCAL}

De acordo com Aghion e Bolton (1997), Barros e Mendonça (1997), Cutler e Katz (1993), Dollar e Kraay (2002), Ferreira (2000), Lusting (2000), Ocampo (2002) e Stallings e Peres (2002), políticas fiscais e monetárias tendem a apresentar resultados insuficientes em termos de crescimento, distribuição de renda e redução na pobreza e, como consequência, induzem o aumento das demandas sociais e dificultam um bom desempenho da economia no longo prazo. Nesta seção, centraremos foco na política fiscal e seu financiamento, e nas políticas sociais e seus impactos.

\subsection{A Política fiscal e seu financiamento}

Caracterizada basicamente pelo gasto púbico, sejam despesas correntes ou em investimentos, e/ou por medidas relacionadas ao comportamento dos impostos, taxas, subsídios, a política fiscal representa um importante instrumento que o Estado possui para intervir na economia.

De acordo com Weeks e Patel (2007), na perspectiva dos programas de estabilização de natureza restritiva, a política fiscal deve ser neutra ou passiva. Isto é, as atividades exercidas pelo governo, nesse aspecto, não devem alterar as preferências dos agentes privados, tampouco interferir em suas escolhas. O mercado deve ser deixado livre para que assim possa alcançar o "ponto único de pleno emprego" que representa a alocação ótima dos recursos. Interferências nesse processo tendem a levar a resultados aquém do pleno emprego. O que em última instância representa um resultado ineficiente.

No entanto, pode ocorrer que essa alocação ótima dos recursos não seja um resultado socialmente desejado (Weeks e Patel, 2007) ${ }^{1}$. Assim sendo, e de acordo com a perspectiva do presente trabalho, a política fiscal deve apresentar outra natureza, qual seja, a de ser ativa e não limitada por objetivos de alocação ótima de recursos. Ou seja, deve ser utilizada para se alcançar os melhores resultados possíveis em termos de crescimento, distribuição de renda e redução na pobreza, e não somente à solvência orçamentária intertemporal². Segundo Rezende et. al. (2001),

1 Sabemos que a definição de qual resultado é ou não socialmente desejado é subjetiva e perpassa por conceitos e definições que fogem ao escopo desse trabalho. Contudo, o que interessa para nossos objetivos é que uma economia que apresenta resultados ruins em termos de crescimento econômico e de redução na desigualdade de renda e na pobreza não deve ser considerado como constituído por instrumentos adequados para se buscar os objetivos desejados pela nação, mesmo que os resultados apresentados por este sejam eficientes. Entendemos ser censo comum que todos desejam viver em uma nação próspera e que essa prosperidade seja repartida da melhor forma possível entre todos.

2 Para uma ampla discussão com relação à natureza e às características do tipo de política fiscal tratada aqui ver: Arestis \& Sawyer (2003a) Arestis \& Sawyer (2003b); Carvalho (1999) e Oreiro et.al. (2003). 
a política fiscal deve seguir três objetivos centrais, quais sejam, ser contra-cíclica, orientada para aumentar o crescimento e para promover a equidade.

No primeiro caso, é fundamental manter uma dinâmica estável de crescimento. Mais ainda, manter uma taxa crescimento estável e alta com menor vulnerabilidade a choques. No segundo, é importante observar que os efeitos das políticas públicas não se restringem ao curto prazo. Assim, os gastos públicos em investimentos, sejam de natureza social, como em educação e saúde, ou em infra-estrutura, são essenciais para aumentar o produto potencial e, deste modo, aumentar a possibilidade de bons resultados em termos de crescimento no médio e no longo prazo.

Finalmente, o terceiro objetivo é a promoção da equidade para evitar a concentração e a centralização da renda e da riqueza. Uma política fiscal ativa e tendo como objetivos básicos a redução da desigualdade de renda e da pobreza deve utilizar seus instrumentos no intuito de modificar essa dinâmica concentradora. Instrumentos tais como implementação de programas de transferências diretas de renda focalizados, desenvolvimento e implementação de uma estrutura tributária progressiva e redistributiva, fundamentada em impostos diretos sobre a renda e a riqueza e programas de subsídios, não somente às atividades produtivas exercidas pelos mais pobres, mas também relacionados às demandas sociais básicas. Como complementação, o governo deve ter atenção especial com relação à criação de uma infra-estrutura social, que possibilite aos mais pobres boas condições de vida: educação, cultura, saúde, saneamento básico, lazer, transporte, emprego.

Com efeito, duas considerações de extrema relevância devem ainda ser feitas. A primeira diz respeito ao conhecido efeito crowding-out ${ }^{3}$. Uma política fiscal de característica contra-cíclica tende a minimizar esse efeito, uma vez que ela não ocupa o espaço dos gastos do setor privado; ao contrário, ela é atuante justamente quando o setor privado não consegue manter um nível socialmente desejado de demanda agregada. Ou seja, os gastos públicos exercem uma função de complemento e não de substituição. Outro ponto importante aqui é a relação entre os gastos públicos e privados. Considerando as especificidades dos países em desenvolvimento, ao invés do efeito crowding-out, tende a ocorrer um efeito crowding-in:

Although orthodox theory insists that public investment crowds out and is less efficient than private investment, there is no firm evidence to support this claim as a general rule across countries. Quite the contrary: there is a large body of evidence indicating that, in low-income countries, public investment generally crowds in private investment both upstream and downstream. Public investment can support private investment and output growth if it expands the country's physical infrastructure (roads,

\footnotetext{
3 O efeito crowding-out ocorre quando um aumento em um componente da demanda agregada resulta na retração de outro. De uma maneira geral, supondo pleno emprego, esse efeito pode ocorrer em função de qualquer modificação na composição da demanda agregada. Contudo, esse efeito, na maioria dos casos, é definido como os possíveis efeitos negativos que os gastos públicos exercem sobre os gastos privados. Para uma discussão mais detalhada a esse respeito, ver: Arestis e Sawyer (2003).
} 
ports and airports, water, sewerage and irrigation systems, electricity-generating capacity and transmission lines), if it boosts labour productivity (for example, through public education and training programs, public transport or public health provision), or if it fosters private savings. When public investment falls, aggregate private profits decline. This reduces both the incentives and the resources available for private investment. (Weeks e Patel, 2007).

A segunda consideração é relacionada às características da dívida pública, bem como sua fonte de financiamento e dinâmica. Como ponto básico, o orçamento do governo deve ser constituído por duas partes: o orçamento corrente, responsável pelos gastos destinados a promover a oferta de bens e serviços públicos, e o orçamento de capital responsável pelos gastos com investimento. Este último possui maior poder de funcionar como anti-cíclico (Keynes, 1936). De acordo com Carvalho (2008) e Oreiro et. al. (2003), a natureza desse tipo de política fiscal é apresentar superávits em períodos de crescimento e déficits em períodos de recessão, o que, em última instância, representaria um equilíbrio intertemporal das contas públicas. Ainda, em virtude do efeito positivo dos investimentos sobre a atividade econômica, esses gastos poderiam criar as condições para os seus financiamentos no médio e longo prazo. Assim, uma situação negativa em termos de resultados fiscais no presente pode não ser um indício de piora nas contas públicas4.

Em relação ao financiamento, a opção de monetização do déficit tende a ser ineficiente por apresentar pouca possibilidade de ser implementada em virtude dos conhecidos efeitos negativos - o principal deles a espiral inflacionária - e por necessitar de condições específicas para ser implementada: uma economia que apresente uma alta e crescente demanda por moeda e/ou uma taxa de inflação já alta.

O financiamento através da arrecadação de impostos e tributos pode ser uma boa opção, embora com uma estrutura tributária regressiva e concentrada em impostos indiretos - que invariavelmente recaem de maneira mais pesada sobre os mais pobres - um possível aumento da arrecadação deve ser tentado via melhora na eficiência e eficácia dos sistemas de arrecadação, buscando uma organização progressiva da estrutura tributária e não na ampliação quantitativa da carga tributária. Como exemplo, a ampliação da base de arrecadação dos impostos e tributos diretos, como os impostos sobre a renda, e, principalmente, uma reorganização do sistema já existente, modificando a estrutura de impostos indiretos em cascata ${ }^{5}$.

\footnotetext{
4 Para uma ampla discussão sobre dívida pública, assim como sua fonte de financiamento e também à sua dinâmica dentro da perspectiva do presente trabalho, ver os trabalhos clássicos: Lerner (1943) e Domar (1944). Para uma discussão atual sobre esse ponto, ver: Carvalho (2008), Oreiro et. al. (2003).

5 Vale ressaltar que essa possibilidade de financiamento é estreitamente ligada à atividade corrente, o que significa que ela tende a ser uma boa alternativa caso o sistema econômico atravesse um período de bom desempenho em termos de crescimento econômico, o que não observamos nos países em desenvolvimento.
} 
Por fim, o financiamento através da venda de títulos da dívida pública, tanto interna quanto externamente, é uma forma importante de administração da política fiscal. Apesar de muitos países em desenvolvimento não possuírem "títulos competitivos", principalmente no mercado internacional, de acordo com Carvalho (2008) essa alternativa parece a mais adequada, uma vez que propicia uma fonte de renda que, se bem administrada pelo governo, tende a minimizar pressões inflacionárias, através do controle sobre a demanda agregada. Para isto, o governo deve ter em conta a dinâmica da dívida pública em virtude do efeito da venda de títulos não somente sobre o montante da dívida, mas também na relação entre a venda dos títulos, o estoque da dívida, os prazos de vencimento dos títulos e o comportamento da taxa de juros ${ }^{6}$.

Neste ponto, um aspecto fundamental deve ser ressaltado, qual seja, a coordenação entre as políticas fiscal e monetária (Bresser-Pereira e Nakano, 2002; Carvalho, 1999; Carvalho, 2008 e Sicsú, 2007). O efeito de uma não deve ser neutralizado ou limitado pela outra. Embora a discussão em relação à política de juros se relacione com a política, seus efeitos sobre a possibilidade de financiamento, mas também sobre a dinâmica da dívida pública, são diretos. Os juros não devem representar uma limitação, tampouco uma sobrecarga, ao serviço da dívida. Com efeito, a manutenção de taxas de juros excessivamente altas reduz a possibilidade de uma política fiscal ativa.

Por último, a dinâmica da dívida deve ser analisada em termos dos objetivos a serem alcançados. A relação entre a dívida pública e a situação orçamentária corrente também deve ser norteada pelos objetivos econômicos e sociais previamente definidos. Situações negativas no curto prazo não necessariamente significam situações negativas no longo prazo. Não se trata aqui de defender políticas expansionistas indiscriminadas que em última instância se reverterão em dívidas insustentáveis e aceleração da inflação ${ }^{7}$. Contudo, limites excessivos para a dívida pública, bem como para o déficit público, além de extrema preocupação com o controle da inflação, restringem a margem de manobra do Estado na tentativa de implementar políticas que promovam um crescimento econômico sustentável e mais equitativo. Essa situação é ainda mais relevante para os países em desenvolvimento em razão da relativa incapacidade do setor privado em exercer o papel de alavancar a economia.

\subsection{Política fiscal e a política social}

A condição de pobreza e a desigualdade de renda são importantes entraves ao processo de crescimento econômico (Blank e Card, 1993; Bourguignon, 2004; Ferreira, 2000; Lustig, 2000). Ainda, os reflexos das políticas macroeconômicas sobre o desempenho da economia e a organização social podem implicar em um agravamento tanto da condição de pobreza quanto

\footnotetext{
6 Não devemos desconsiderar que o que se observa nos países em desenvolvimento em relação às interações entre a dinâmica da dívida e as taxas de juros praticadas é uma transferência de renda por parte dos governos para os mais ricos, que representam a classe credora.

7 A aceleração da inflação tende a ocorrer caso os gastos do governo representem um excesso de demanda, o que não é o caso aqui em virtude
} da natureza contra-cíclica da política fiscal. 
da desigualdade de renda da população (Michel, 2003; Ocampo, 2004; Rocha, 2000). Políticas macroeconômicas restritivas, com excessiva preocupação em combater a inflação e gerar superávits primários tendem a gerar baixo nível de crescimento econômico, o que implica baixa geração de emprego e renda, agravando, assim, a situação dos mais pobres. Isto pode gerar um círculo vicioso difícil de se reverter.

Considerando que é esse o tipo de política macroeconômica implementada na maioria dos países em desenvolvimento, bem como no Brasil, observamos um processo circular que tem como resultado a manutenção de uma grande parte da população abaixo da linha de pobreza e com poucas oportunidades de superarem suas dificuldades.

As políticas sociais, nesse sentido, representam um importante instrumento. No entanto, é importante definir o que trataremos aqui de política social. De acordo com Castro et. al. (2008) as políticas sociais representam um conjunto de programas destinados a reconhecer e proporcionar à população condições básicas de vida. Para a definição de condições básicas, nesse aspecto, além de bens e serviços, leva-se em consideração a condição de cidadania, ou seja, as políticas sociais são medidas tomadas tendo como objetivo proporcionar aos indivíduos condições de serem cidadãos com direitos, e também deveres, de participarem do meio social do qual fazem parte?.

\subsubsection{Instrumentos de Políticas sociais no Brasil ${ }^{10}$}

Desde o início do século XX a preocupação com as questões sociais esteve presente nas agendas políticas do Estado. O surgimento e a consolidação dos Estados de Bem-Estar representam a relevância do aspecto social. Dentro desse paradigma os Estados Nacionais podem ser entendidos como organizadores de sistemas de garantias legais tendo por objetivo possibilitar, fora da esfera privada, o acesso a bens e serviços que assegurem a proteção social do indivíduo em face de alguns riscos e vulnerabilidades sociais. Incluem-se aqui ações no sentido de proteção contra riscos sociais (como doenças, velhice, morte, desemprego), ações contra a pobreza (programas de mínimos sociais) e de garantia de acesso aos serviços de educação e saúde (Cardoso Jr. e Jaccoud, 2005).

Inicialmente restrito ao âmbito da população que fazia parte do mercado de trabalho formal, o campo de atuação das políticas sociais foi se ampliando à medida que o mercado de trabalho assalariado foi incorporando parcelas cada vez maiores da população e também com uma

8 Para uma análise quantitativa dessa questão ver: Agénor (2001), Agenór (2002), Blank \& Blinder (1985), Ravallion \& Chen (1996). Para o caso da economia brasileira ver: Amadeo e Neri (2000), Barros (2000) e Barros e Mendonça (1997).

9 Trataremos aqui das políticas sociais implementadas pelo governo federal. Essa opção metodológica em nada prejudica a análise, mesmo porque, em que pese a relativa autonomia das esferas subnacionais, o governo central em grande medida orienta, direta ou indiretamente, a construção e execução das principais políticas sociais. Ainda, considerando a heterogeneidade dessas políticas em nível estadual e municipal, uma análise que desse conta desse escopo vai muito além da proposta do presente trabalho.

10 Para uma ampla discussão com relação às orientações seguidas nessa parte do trabalho ver Peliano (2006). 
crescente associação entre o Estado e os agentes privados nas atividades de assistência social, exercendo o Estado, nesse aspecto, um papel secundário, de apoio financeiro direto e indireto.

Na medida em que o Estado reconhecia como direitos sociais o acesso à educação, à saúde, à proteção social, não somente para os que faziam parte da classe trabalhadora assalariada, mas para o conjunto da população, foi sendo inserido na formatação das políticas sociais o conceito de cidadania (Jaccoud, 2009). Esse fator foi, e ainda é, fundamental para a mudança de rumos observada no conjunto das políticas sociais já no fim do século XX. Se no início as políticas sociais focavam aliviar uma situação de "pobreza operária", o momento posterior é caracterizado por uma política mais ampla, tanto relacionada ao público-alvo quanto ao seu escopo. ${ }^{11}$

A mudança no ritmo de crescimento econômico reforçado pelo desempenho ruim na década de 1980 evidenciou as limitações da política de proteção aos riscos sociais centrada na política previdenciária. $\mathrm{O}$ aumento no número de desempregados colocava em xeque a estratégia de incorporação social via aumento dos trabalhadores formais. Ainda, fortalecia-se o argumento de que tanto o combate à pobreza pela iniciativa privada (filantropia) como sua superação via desenvolvimento econômico, não seriam suficientes uma vez que a dinâmica da pobreza passava a ser tratada, no debate nacional, como característica estrutural. Neste sentido, abriu-se espaço para que o combate à pobreza passasse a ser tratado como tema próprio e prioritário da ação social do Estado (Cardoso Jr. e Jaccoud, 2005; Jaccoud, 2009).

Diante desse conjunto de questões, impasses e preocupações, houve uma ampla discussão sobre as políticas sociais que, posteriormente, se incorporou à agenda da constituinte de 1988 no Brasil. A importância da década de 1980 advém da agenda de reformas que se constituiu tanto no concernente às políticas sociais quanto à própria questão social. De acordo com Cardoso Jr. e Jaccoud (2005), esta agenda reformista foi reflexo de dois processos: a) a mobilização social e política na tentativa de redemocratização do país, em torno da qual amplos setores da sociedade se organizaram na busca do atendimento de demandas sociais reprimidas desde 1964; b) a crise do "milagre econômico" que evidenciava os limites do modelo de desenvolvimento nacional relacionados à inclusão dos setores mais desfavorecidos.

Conforme Jaccoud (2009), a Carta Magna lançou as bases para uma significativa mudança nas diretrizes da política social, ampliando os direitos sociais e a proteção social sob responsabilidade estatal, com impactos relevantes no que diz respeito ao desenho das políticas, à definição dos beneficiários e dos benefícios ${ }^{12}$. A partir da Constituição de 1988, as políticas sociais brasileiras passaram a ter como

11 Contudo, apesar dessas importantes modificações na orientação da política social, a incorporação dos trabalhadores do setor informal e daqueles vinculados à economia de subsistência urbana e rural ainda permanece como um desafio para uma política de proteção social ainda largamente fundamentada no princípio do seguro social e majoritariamente financiada por contribuições sociais.

12 A nova Constituição espelhou os ideais universalistas ligados a uma idéia ampla de cidadania, buscando aumentar a cobertura das políticas sociais no que diz respeito a bens, serviços, garantias de renda e equalização de oportunidades. Ela tentou superar um sistema marcado pelo autofinanciamento, excludente e não-distributivo, procurando instituir as bases para a organização de um sistema universal e garantidor de direitos (Cardoso Jr. e Jaccoud, 2005). 
finalidade dar cumprimento aos objetivos fundamentais da República, conforme previsto no seu Art. $3^{\circ}$. Assim, por intermédio da garantia dos direitos sociais, buscar-se-ia construir uma sociedade livre, justa e solidária, erradicar a pobreza, a marginalização, reduzir as desigualdades sociais e regionais e promover o bem de todos sem preconceitos ou quaisquer formas de discriminaçã̃o ${ }^{13}$. Dessa forma, a implementação das diretrizes constitucionais nos anos 1990 possibilitou o país atravessar um período marcado por uma ampla agenda de reformas no que se refere à ação social do Estado, que tiveram como resultado profundas mudanças no perfil e na organização do chamado Sistema Brasileiro de Proteção Social - SBPS (Castro e Cardoso Jr., 2005; Cardoso Jr. e Jaccoud, 2005) ${ }^{14}$.

Juntamente ao processo de reorganização e redemocratização do Estado brasileiro que deriva das determinações da Carta Constitucional, outros fatores atuaram no sentido de construir uma nova institucionalidade no âmbito das políticas sociais. É importante ressaltar, nesse sentido, o fato de que a agenda de reformas sociais foi renovada durante a década de 1990, seja em decorrência das restrições econômicas apresentadas e sua consequente limitação orçamentária, seja, ainda, por influência de uma nova vertente no debate, a qual reivindica a necessidade de priorizar o combate à pobreza. Durante este período, emergiu uma nova agenda política que radicaliza o diagnóstico da gestão da pobreza, elevando-a ao status de principal, senão único, objetivo legítimo da política pública no campo social (Cardoso Jr. e Jaccoud (2005); Jaccoud, 2009).

De acordo com Cardoso Jr. e Jaccoud (2005) e Castro et. al. (2008), esses movimentos em torno da política social, principalmente no período pós-Constituição, destacam dois tipos de políticas: as de Estado e as de governo. Os processos históricos dessas políticas demonstram que elas têm tratamento diferenciado, sendo função do cenário econômico. Enquanto o primeiro tipo tem caráter anti-cíclico e uma configuração jurídico-institucional que tende a preservá-la de cortes, o segundo tipo é, em grande medida, dependente da conjuntura política e econômica e normalmente é manipulada de acordo com os interesses dos governantes. Isso faz com que a crescente estrutura da política social brasileira necessite de uma consolidação e de um aprofundamento, uma vez que, mesmo apresentando importantes resultados positivos, ainda apresenta problemas, tanto com relação à sua formulação quanto à sua implementação.

Dentro dessa nova organização da política social no Brasil, segundo Draibe (2003), Cardoso Jr. e Jaccoud (2005), Castro e Cardoso Jr. (2005) e Castro et. al. (2008) o SBPS pode ser dividido em quatro grandes blocos, os chamados "Eixos Estruturantes das Políticas Sociais", quais sejam, emprego e trabalho, assistência social e combate à pobreza, direitos incondicionais de cidadania social e infraestrutura social.

13 Um ponto fundamental dentro dessa perspectiva é o estabelecimento, no Art. $7^{\circ}$ (inciso IV), do salário mínimo, fixado em lei, nacionalmente unificado, com a finalidade de atender as necessidades vitais dos trabalhadores. Tão fundamental, foi o estabelecimento do princípio da vinculação entre o salário mínimo e o piso dos benefícios previdenciários e assistenciais permanentes.

14 Sistema Brasileiro de Proteção Social - SBPS - é um conjunto de políticas e programas governamentais destinados à prestação de bens e serviços e à transferência de renda, com o objetivo de cobertura de riscos sociais, garantia de direitos sociais, equalização de oportunidades e enfrentamento das condições de destituição e pobreza. 
As principais políticas que representam e caracterizam cada um dos "eixos" descritos acima estão resumidas no quadro 1 abaixo.

Quadro 1 | Abrangência da política social do governo federal, por áreas de atuação e principais programas/ações

\begin{tabular}{|c|c|c|}
\hline Eixos Estruturantes & Áreas de atuação & Principais programas e ações \\
\hline \multirow{10}{*}{$\begin{array}{l}\text { 1. Emprego e } \\
\text { Trabalho }\end{array}$} & 1. Previdência social & $\begin{array}{l}\text { - Previdência Social Básica (Regime Geral de Previdência Social) - } \\
\text { pagamento de aposentadorias, pensões e auxílios-doença }\end{array}$ \\
\hline & \multirow{3}{*}{$\begin{array}{l}\text { 2. Benefícios a } \\
\text { servidores } \\
\text { públicos federais }\end{array}$} & - Previdência de Inativos e Pensionistas da União (Regime Jurídico Único) \\
\hline & & - Assistência Médica e Odontológica aos Servidores \\
\hline & & - Auxílio-alimentação/refeição e transporte \\
\hline & \multirow{4}{*}{$\begin{array}{l}\text { 3. Emprego e } \\
\text { proteção ao } \\
\text { trabalhador }\end{array}$} & - Qualificação Social e Profissional do Trabalhador \\
\hline & & - Integração das Pol. Públ. de Emprego, Trabalho e Renda \\
\hline & & - Seguro-Desemprego \\
\hline & & - Abono Salarial PIS/Pasep \\
\hline & \multirow{2}{*}{$\begin{array}{l}\text { 4. Desenvolvimento } \\
\text { agrário }\end{array}$} & - Apoio ao pequeno produtor rural; e \\
\hline & & - Reforma Agrária-assentamentos sustentáveis p/trabalhadores rurais \\
\hline \multirow{6}{*}{$\begin{array}{l}\text { 2. Assistência Social } \\
\text { e Combate à } \\
\text { Pobreza }\end{array}$} & \multirow{4}{*}{ 5. Assistência social } & - Transf. de Renda com Condicionalidades - Bolsa Família \\
\hline & & - Proteção Social à Pessoa Portadora de Deficiência (RMV e BPC/Loas) \\
\hline & & - Proteção Social à Pessoa Idosa (RMV e BPC/Loas) \\
\hline & & - Erradicação do Trabalho Infantil \\
\hline & \multirow{2}{*}{$\begin{array}{l}\text { 6. Alimentação } \\
\text { e nutrição }\end{array}$} & - Apoio à Alimentação Escolar na Educação Básica \\
\hline & & - Aquisição de Alimentos Provenientes da Agricultura Familiar \\
\hline \multirow{14}{*}{$\begin{array}{l}\text { 3. Direitos } \\
\text { Incondicionais de } \\
\text { Cidadania Social }^{3}\end{array}$} & \multirow{4}{*}{ 7. Saúde } & - Atenção Básica em Saúde \\
\hline & & - Atenção Hospitalar e Ambulatorial no Sistema Único de Saúde \\
\hline & & - Vigilância Epidemiológica e Controle de Doenças Transmissíveis \\
\hline & & $\begin{array}{l}\text { - Vigilância, Prevenção e Atenção em HIV/Aids e outras Doenças } \\
\text { Sexualmente Transmissíveis }\end{array}$ \\
\hline & \multirow{7}{*}{ 8. Educação } & - Erradicação do analfabetismo \\
\hline & & - Educação infantil \\
\hline & & - Ensino fundamental \\
\hline & & - Ensino médio \\
\hline & & - Ensino superior (graduação e pós-graduação) \\
\hline & & - Ensino profissionalizante \\
\hline & & - Educação de Jovens e Adultos (EJA) \\
\hline & \multirow{3}{*}{ 9. Cultura } & - Etnodesenvolvimento das Sociedades Indígenas \\
\hline & & - Produção e Difusão Cultural \\
\hline & & - Preservação do Patrimônio Histórico \\
\hline \multirow{4}{*}{$\begin{array}{l}\text { 4. Infra-Estrutura } \\
\text { Social }\end{array}$} & \multirow{2}{*}{$\begin{array}{l}\text { 10. Habitação } \\
\text { e urbanismo }\end{array}$} & - Infra-estrutura Urbana \\
\hline & & - Morar Melhor e Nosso Bairro \\
\hline & \multirow{2}{*}{$\begin{array}{l}\text { 11. Saneamento e } \\
\text { meio ambiente }\end{array}$} & - Saneamento Básico e Saneamento é Vida \\
\hline & & - Pró-Água, infra-estrutura e outros \\
\hline \multicolumn{3}{|c|}{ Fonte: Disoc//pea, SOF/LOA e PPA, apud Castro et. al. (2008). } \\
\hline $\begin{array}{l}\text { Nota: Na metodologi } \\
\text { (INSS) são tratadas d } \\
\text { analisados na área d }\end{array}$ & tilizada neste e em tra & $\begin{array}{l}\text { alhos anteriores, as despesas do Regime Geral de Previdência Social } \\
\text { sas com os inativos e dos pensionistas do Regime Jurídico Único, que são } \\
\text { vidores públicos federais. }\end{array}$ \\
\hline
\end{tabular}


Compondo o Eixo da Assistência Social e Combate à Pobreza, e tendo como objetivo a ampliação da intervenção do Estado no campo da proteção social e a focalização nos mais pobres, a década de 2000 inaugurou uma nova vertente de políticas federais no campo da assistência social: as políticas de transferência de renda. No âmbito federal, os principais programas de transferência de renda tiveram início em 2001, com a criação do Programa Bolsa Escola, do Programa Nacional de Renda Mínima vinculado à saúde, e dos Programas Bolsa-Alimentação e Auxílio-gás, este último vinculado ao Ministério das Minas e Energia. Em 2003, foi criado o Cartão Alimentação do Programa Fome Zero e ainda o Programa Bolsa Família que atualmente é o principal programa de transferência direta de renda do governo federal, administrado pelo Ministério do Desenvolvimento Social e Combate à Fome.

Essas políticas sociais de transferência direta de renda vêm desempenhando um papel fundamental no combate à pobreza e também contribuindo sobremaneira para a redução da desigualdade de renda. Com um baixo crescimento do PIB, média anual de 2,5\%, a considerável queda observada no nível de pobreza, cerca de 10\%, é diretamente relacionada à queda na desigualdade. Barros et. al. (2007b) apontam que a renda per capita dos mais pobres cresceu substancialmente entre 2001 e 2005. Entre 2006 e 2013 este número se elevou ainda mais, apesar da relativa estagnação da renda per capita nacional ${ }^{15}$. Houve um crescimento anual de $8 \%$ para os $10 \%$ mais pobres e de $5,9 \%$ para os $20 \%$ mais pobres, ao passo que a renda dos $10 \%$ mais ricos declinou $0,3 \%$ e a dos $20 \%$ mais ricos caiu $0,1 \%$. Mais especificamente, a taxa de crescimento da renda dos 10\% mais pobres foi 37 pontos percentuais maior que a dos $10 \%$ mais ricos e a taxa de crescimento da renda dos $20 \%$ mais pobres foi 26 p.p. superior à dos $20 \%$ mais ricos ${ }^{16}$.

Considerando os fatores determinantes dessas alterações no perfil distributivo da renda, Barros et. al. (2007a), a partir de uma análise contrafactual, identificaram como principais determinantes da queda da desigualdade nos últimos anos a expansão das transferências governamentais e as mudanças ocorridas no mercado de trabalho. Segundo esse estudo, cerca de $50 \%$ do declínio da desigualdade resultou da evolução da renda não derivada do trabalho, principalmente das transferências governamentais, apesar desta representar menos de 1/4 da renda total. Mudanças na distribuição da renda do trabalho explicam cerca de $1 / 3$ da queda observada na desigualdade, embora essa renda represente mais de $3 / 4$ da renda total.

Uma análise da importância dos programas de transferência para combater a pobreza no Brasil no início da década de 2000 foi realizada por Soares et. al. (2006), com base nos dados da PNAD de 2004. Este trabalho mostrou que os programas de transferências são bem focalizados: as

\footnotetext{
15 Importante ressaltar que para esses números, em função da limitação de informações, não é considerada a renda advinda da remuneração de ativos financeiros.

16 Em geral, o impacto do crescimento econômico sobre a pobreza é tanto maior quanto menor for a desigualdade na distribuição de renda. Reduções no grau de desigualdade não apenas têm impacto direto sobre a pobreza, como também elevam a capacidade do crescimento econômico beneficiar os mais pobres. É evidente que o inverso também é verdadeiro: o crescimento não apenas tem impacto direto sobre a pobreza, como também eleva a capacidade de futuras reduções no grau de desigualdade reduzirem a pobreza. (Barros et.al. 2007b).
} 
famílias mais pobres recebem a maior parte dos recursos transferidos por esses programas e é praticamente irrelevante o número de beneficiários entre a população de renda mais alta. Além disso, as transferências reduzem a incidência e a intensidade da pobreza bem como a desigualdade. Ainda, neste mesmo estudo, é possível observar, como esperado, que todas as transferências de renda promovem a redução da pobreza. Contudo, em razão dos valores transferidos, o Benefício de Prestação Continuada (BPC) $)^{17}$, as pensões e as aposentadorias do piso de um salário mínimo são capazes de retirar as famílias da indigência e da pobreza, ao passo que os demais programas de transferência de renda melhoram a situação das famílias sem, no entanto, serem suficientes para retirar todas elas da condição de pobreza. Em outras palavras, enquanto o BPC, as aposentadorias e as pensões do piso de um salário mínimo têm impactos claros e diretos sobre a incidência e a intensidade da pobreza, as demais transferências têm efeito forte apenas sobre a intensidade da pobreza ${ }^{18}$.

\subsection{Políticas macroeconômicas, combate à pobreza e a melhoria da distribuição de renda: a política monetária}

A política monetária, ao afetar o nível de atividade econômica e a composição do produto, produz reflexos diretos sobre o nível de emprego, assim como sobre a distribuição da renda e da riqueza. Possui, portanto, efeitos não somente no curto prazo, mas também no longo prazo, influenciando, desta forma, políticas sociais. De fato, mais do que os efeitos sobre estabilidade macroeconômica, a política monetária deve também ser analisada a partir de seus efeitos distributivos, uma vez que afeta distintamente diferentes grupos de renda, conforme salienta Saad Filho (2007).

O que se observa, principalmente após o final da década de 1970 com o artigo clássico de Kydland \& Prescott (1977) sobre a inconsistência intertemporal de planos ótimos, é que a política monetária deveria se preocupar fundamentalmente em apenas conter a inflação, evitando múltiplos objetivos. ${ }^{19}$ A partir da hipótese de que a política monetária seja neutra no longo prazo, eventuais efeitos sobre renda e emprego de políticas monetárias expansionistas tendem a se dissipar no longo prazo. Neste caso, efeitos distributivos sobre renda e riqueza não são relevantes na análise. Mais ainda, se a moeda é neutra no curto prazo, não há efeitos

17 O Benefício de Prestação Continuada é uma transferência de renda, sem condicionalidades e independente de contribuição prévia para o regime de seguridade social, para idosos com 65 anos ou mais e pessoas com deficiência, não aptas ao trabalho e a uma vida independente, que vivem em famílias com renda familiar per capita abaixo de $1 \frac{1}{4}$ do salário mínimo. Previsto na Constituição Federal, o BPC começou a ser implementado a partir de 1996. O valor do benefício é igual a um salário mínimo. No caso de deficientes, médicos peritos avaliam sua condição física e mental para uma vida independente de trabalho. Os beneficiários - tanto idosos como deficientes - são reavaliados a cada dez anos para examinar se sua situação de extrema pobreza mudou. O benefício pode ser cancelado caso a situação da família não seja mais de extrema pobreza.

18 Para uma descrição detalhada dos principais programas de transferência de renda executados atualmente pelo governo federal além do $\mathrm{BPC}$, ver Soares et. al. (2006).

19 Barro \& Gordon (1983) apresentam um modelo que inclui credibilidade na política monetária. 
sobre emprego e renda no longo prazo e os efeitos de curto prazo de políticas contracionistas se dissipam no longo prazo, não havendo "path dependence". Este é um ponto importante e que será retomado mais à frente.

A política monetária recente, tanto nos países da OCDE, quanto nos países em desenvolvimento, segue uma regra simples com a determinação da taxa de juros e uma comunicação do Banco Central de modo a garantir maior credibilidade. Em geral, acompanhado da determinação da taxa de juros, os Bancos Centrais operam com metas explícitas ou implícitas de inflação.

Sem entrar em detalhes técnicos do modelo, seu funcionamento de modo geral pode ser descrito da seguinte forma: a autoridade monetária define a meta de inflação a ser atingida. Através de algumas funções de reação - em geral uma função de demanda agregada, uma de oferta agregada, uma para a taxa de câmbio e uma para a taxa de juros ${ }^{20}$ - construídas pela autoridade monetária e constituídas pelos parâmetros que esta julga pertinentes, ela monitora o desempenho da inflação e desemprego. Observada a dinâmica do sistema, a autoridade monetária manipula a taxa de juros na tentativa de influenciar as expectativas dos agentes privados assim como o nível de demanda agregada para atingir a meta de inflação pré-estabelecida.

Embora bastante difundida, essa modelagem para a política monetária tende a não ser uma boa alternativa quando se tem como objetivo, ao invés de um controle severo sobre a taxa de inflação, uma trajetória de altas taxas de crescimento com distribuição de renda e redução da pobreza ${ }^{21}$.

Seguindo Saad Filho (2007) e Sicsú (2002), alguns outros pontos devem ser considerados, principalmente do ponto de vista dos países em desenvolvimento, já que o modelo de metas de inflação em interação com as estruturas econômicas e políticas desses países tendem a produzir resultados insuficientes em termos de crescimento econômico, além de ser um modelo de política monetária que se preocupa com os resultados agregados, sendo que os impactos e os efeitos em termos de distribuição de renda e de pobreza derivados dessas políticas nem sempre são levados em consideração:

- Os custos de se ter uma meta de inflação muito baixa: na maioria das vezes a meta de inflação é excessivamente baixa. Na tentativa de transparecer credibilidade, a autoridade monetária pode levar a economia para uma situação de baixo crescimento econômico, alto desemprego e crescentes problemas sociais;

20 A manipulação da taxa de juros, o ponto chave do modelo de metas inflacionárias, é ditada por uma regra conhecida como Regra de Taylor. Basicamente, o governo aumenta a taxa de juros se a inflação corrente é mais alta do que o esperado, ou ao contrário, diminui a taxa de juros se a inflação é mais baixa do que o esperado, ou seja, as taxas de juros são ajustadas de acordo com as flutuacões do produto e com as variações da taxa de inflação e, assim, o governo tenta, através desse instrumento, atingir a meta de inflação previamente definida. Para uma descrição da operacionalidade da Regra de Taylor ver o trabalho que inseriu esse instrumento no âmbito da política monetária: Taylor (1993).

21 Para uma ampla discussão a respeito da eficiência e eficácia dos modelos de metas de inflação ver: Sicsú (2007), parte V. 
- Os custos de altas taxas reais de juros: a utilização da taxa de juros como único instrumento de controle da atividade econômica tende a mantê-la em níveis mais altos do que o necessário. Embora seja eficiente para controlar a inflação, esta situação pode levar à estagnação e a aumentar a concentração de renda;

- Os custos dos descompassos entre o modelo de metas de inflação e o equilíbrio na Balança Comercial: para uma economia aberta e com taxas de câmbio flutuantes, variações na taxa de juros levam a variações na taxa de câmbio, o que dificulta políticas públicas de longo prazo e também as atividades do setor privado, principalmente as relacionadas aos investimentos. Taxas de juros excessivamente altas podem representar uma taxa de câmbio sobrevalorizada, o que implica aumento das importações e diminuição das exportações, podendo gerar efeitos deletérios de longo prazo para alguns setores industriais. Este parece ser o caso recente do Brasil;

- Os custos dos descompassos entre o modelo de metas de inflação e a estabilidade do sistema financeiro: o Banco Central, nesse contexto, acumula suas funções habituais (banco dos bancos, banqueiro do governo e executor da política monetária), além de ser a instituição responsável em operacionalizar o modelo de metas de inflação. Embora não represente um fardo pesado em termo de atribuições, essas funções podem entrar em conflito caso as sinalizações do mercado de bens e serviços forem contrárias às do mercado financeiro. Um aumento de juros para conter uma pressão de demanda pode representar um aumento das obrigações no mercado financeiro, que para muitos agentes e até mesmo para o governo pode significar uma situação de crise financeira. A crise de 2007/08 e a subsequente crise na periferia do Euro demonstrou a importância e o papel dos bancos centrais como emprestadores em última instância.

Deste modo, a excessiva preocupação com o controle da inflação e as políticas construídas para esse fim tendem a limitar a capacidade de crescimento da economia. Assim, na perspectiva dos países em desenvolvimento, é fundamental uma mudança na orientação das políticas. $\mathrm{O}$ controle da inflação, ao invés de ser o ponto central, deve ser entendido como consequência de políticas monetárias destinadas a promover o crescimento econômico e a distribuição de renda. Além da mudança nos objetivos a serem perseguidos e na concepção sobre o papel do Estado como agente econômico, alterações não somente nos instrumentos, mas também na própria execução da política monetária devem ser implementadas (Ocampo, 2002; Sicsú, 2008).

O modelo de metas de inflação, apesar dos problemas apresentados, pode ser considerado uma importante ferramenta no controle da inflação ${ }^{22}$. Contudo, seus objetivos de curto prazo podem ser incompatíveis com uma estratégia de longo prazo de crescimento com distribuição

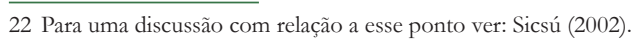


de renda e redução na pobreza. A inserção, e principalmente, a consideração de parâmetros que forneçam informações sobre o perfil distributivo e a dinâmica da pobreza poderia propiciar resultados socialmente mais aceitáveis. Neste sentido, é importante salientar aqui que supõe-se, explicitamente, que - ao contrário dos modelos de metas de inflação utilizados pela maior parte dos bancos centrais - admitimos que as políticas fiscal e monetária têm efeitos de longo prazo sobre a distribuição de renda e riqueza. Políticas monetárias sistematicamente contracionistas inevitavelmente produzem efeitos distributivos no curto prazo e que não são corrigidos no longo prazo. Com efeito política tributária distributiva pode compensar estes efeitos.

A maior integração do comércio mundial aliada à liberalização do mercado financeiro, principalmente nos países em desenvolvimento após 1990, resultaram em uma piora relativa na situação dos mais pobres, pois proporcionou um aumento na desigualdade da renda e da riqueza, além de aprofundar as disparidades relacionadas ao poder político e econômico. Arestis (2004) sugere que a organização e, principalmente, a orientação do sistema financeiro nos países em desenvolvimento deve ser buscar, como objetivo principal, um crescimento econômico estável, sustentável e equitativo. Para tanto, políticas que proporcionam financiamento em volume e preços adequados para os investimentos e para os gastos sociais são essenciais neste propósito. ${ }^{23}$

Muitas são as opções de que dispõe o Banco Central para implementar uma política monetária nesse sentido. Como exemplos, temos: programas para alocação de crédito para setores estratégicos; estabelecimento de metas de empréstimo para atividades que não apresentam uma taxa alta de lucro, mas são vitais para a população mais pobre, como os pequenos agricultores e as pequenas empresas; criação e fortalecimento dos Bancos de Desenvolvimento e Agências de Fomento; programas de garantia de crédito com o intuito de reduzir os riscos dos investimentos de médio e longo prazos, abertura de espaço para a atuação de instituições de micro-crédito, entre outras.

Outro ponto crucial diz respeito à utilização da taxa de juros como instrumento de controle do nível da atividade econômica. Como discutido acima, ao exercer essa função a taxa de juros pode desempenhar papéis contraditórios. Mais ainda, ao acumular funções - equilibrar o nível de investimento e de poupança, equilibrar o Balanço de Pagamentos e controlar a inflação - a taxa de juros tende a ser excessivamente alta. Dentro dessa perspectiva, o papel da taxa de juros seria somente o de equilibrar o mercado financeiro, sendo auxiliada nessa tarefa por "metas de crédito", na tentativa de incentivar investimentos em setores caracterizados por apresentarem externalidades positivas, e serem socialmente importantes ${ }^{24}$.

23 Para uma discussão a esse respeito ver: Epstein e Grabel (2007); Arestis, Nissanke \& Stein (2003), Ocampo \& Taylor (1998), bem como CEPAL (2002).

24 Mesmo reconhecendo a efićácia da taxa de juros em controlar a demanda agregada, esse papel deve ser exercido pela política fiscal, pois assim a taxa de juros pode ser mantida a níveis mais baixos, o que facilita a execução da política fiscal, já que o nível de investimentos tenderia a aumentar e os serviços da dívida pública a diminuir. Por último, o equilíbrio no Balanço de Pagamentos seria deixado à cabo de políticas específicas a esse fim: políticas de incentivo às exportações; políticas de controle sobre as importações; regulação dos investimentos externos e das transferências. 
Para operacionalizar essas alterações, um instrumento possível seria a política de controle de capitais. Isto porque, dadas a abertura comercial e a volatilidade dos fluxos monetários internacionais, seria difícil construir uma tentativa de mudança de orientação e objetivos como a discutida aqui. As razões para isso derivam da possibilidade de uma fuga de capitais que tal estratégia poderia resultar devido à redução dos juros, da necessidade de autonomia na execução da política monetária que um regime totalmente liberal e aberto não proporciona, de força e de poder, político e econômico, para promover medidas que atendam aos objetivos pré-estabelecidos, mas que podem ser contrárias aos interesses do mercado financeiro (Lustig, 2000).

Ainda em relação à mudança de objetivos, principalmente no que tange à preocupação excessiva em controlar a inflação, vale ressaltar que a sustentação empírica do trade-off entre inflação e crescimento, ou inflação e desemprego não é consolidada. Ao contrário, alguns trabalhos evidenciam que a suposição de que essas variáveis são fortemente correlacionadas pode ser excessivamente forte ${ }^{25}$. De acordo com Saad Filho (2007), esta relação não pode ser tratada como uma regra geral e concebida como dada. Assim, tal relação, caso exista, é fruto dos processos históricos e depende tanto do desenvolvimento institucional quanto das políticas econômicas.

Por último, mas não menos importante, merece consideração discutir alguns impactos da inflação sobre a distribuição de renda. As políticas que priorizam o controle da inflação, apesar de reconhecerem que a aceleração dos preços tem um caráter altamente regressivo, concentram suas análises em proposições gerais e agregadas. Entendem que os mais pobres são mais afetados pela inflação, pois possuem menores alternativas para protegerem seus rendimentos, por manterem, se não a totalidade, uma grande parte dos rendimentos em moeda corrente. Além disso, porque têm no salário sua principal fonte de renda - sendo esse fixo em termos nominais - um aumento de preços representa uma perda real de poder de compra.

Em que pese o fato dessas proposições serem, em geral, observadas, outros efeitos também importantes devem ser analisados. Considerando a relação entre a inflação e a queda do salário real, a contrapartida pode ser um aumento no nível de emprego, já que os custos para o empregador em termos de salários estão mais baixos. Assim, se o "efeito-emprego" superar o "efeito-salário", os efeitos em termos de redução da desigualdade e da pobreza podem ser contrários aos inicialmente propostos. Ainda, assim como a inflação tem a característica de desvalorizar os salários reais em termos nominais, o faz também com relação aos compromissos e dívidas fixados em termos nominais; e não é irreal supor que os mais pobres tendem a se encontrar na posição de devedores. A concentração espacial dos mais pobres assim como a atividade por eles exercida também deve ser analisada, pois as proposições gerais acima podem caracterizar bem grupos que vivem em áreas urbanas, mais vulneráveis aos efeitos do mercado financeiro e do mercado de trabalho. Contudo, caso se concentrem em áreas rurais, os efeitos regressivos da inflação podem ser menos severos sobre eles, porque

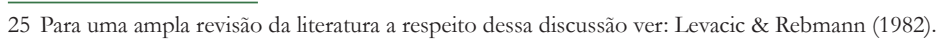


o aumento no nível de preço pode representar algum ganho relativo advindo de algum produto por eles produzido. Ainda, no tocante aos efeitos regressivos da inflação sobre os rendimentos, a "classe média” parece ser relativamente mais vulnerável do que os mais pobres (Saad Filho, 2007) ${ }^{26}$.

Vale ressaltar que não há aqui nenhum tipo de argumento em defesa de taxas altas de inflação e muito menos de que a aceleração dos preços seja um fator positivo para o desempenho da economia. O ponto central é destacar que, em que pesem os efeitos regressivos da inflação, os resultados alcançados pelas políticas monetárias restritivas que são parte dos programas de estabilização antiinflacionários podem ser ainda mais danosos para os mais pobres, pois esses tiveram como consequência crescimento econômico reduzido, aumento na taxa de desemprego, ampliação dos serviços da dívida pública e diminuição da capacidade do governo em atender às demandas sociais.

\section{CONCLUSÕES}

Este artigo teve como objetivo inserir a discussão sobre a pobreza e a desigualdade de renda no âmbito da política macroeconômica. Para tanto, consideramos a diminuição da taxa de pobreza e a melhora da distribuição da renda como objetivos centrais a serem definidos na formulação e implementação das políticas públicas.

A literatura demonstra que políticas macroeconômicas restritivas, com excessiva preocupação em combater a inflação e garantir solvência intertemporal, independentemente de seus efeitos sobre o bem-estar, tendem a gerar baixo nível de crescimento econômico, o que implica baixa geração de emprego e renda, agravando, assim, a situação dos mais pobres.

Ainda, considerando os importantes efeitos negativos que as recessões exercem sobre os mais pobres tanto no curto quanto e, principalmente, no longo prazo, uma estratégia de crescimento voltada para o combate à pobreza e à desigualdade de renda deve ser sustentada por políticas que minimizem as flutuações na atividade econômica e dotada de instrumentos capazes de reduzir as vulnerabilidades da economia frente às crises, tanto internas quanto externas. Nesse sentido, construir mecanismos de proteção social representa mais que uma estratégia de combate à pobreza e à desigualdade de renda, representa uma consistente estratégia de crescimento sustentado e equilibrado no longo prazo. As políticas sociais, nesse sentido, representam um importante instrumento. Contudo, essas políticas são instrumentos auxiliares, importantes, mas, em grande medida, função das políticas macroeconômicas e também da atividade econômica.

É nesse sentido que, para que o combate à pobreza e à desigualdade de renda se torne eficaz, é necessária a inserção desses temas no âmbito da formulação e da implementação das políticas

26 Neste sentido, ver também: Lusting (2000); Arestis (2004) e Ferreira et. al. (2000). 
macroeconômicas. A redução do número de pessoas pobres e uma distribuição mais equitativa da renda não devem ser consideradas como consequências das políticas econômicas, mas objetivos centrais a serem perseguidos. Para tanto, assim como metas de inflação e de superávits primários, a inserção de metas de redução na taxa de pobreza e de redução nos indicadores de desigualdade de renda concederia à política macroeconômica uma perspectiva de crescimento estável, sustentado e que favoreça a população como um todo.

Enfrentar a problemática da pobreza e da distribuição de renda e riqueza não é tarefa simples, e requer tempo para que resultados consistentes sejam alcançados. No entanto, inserir o combate à pobreza no âmbito da formulação e da implementação das políticas macroeconômicas é o ponto de partida para uma agenda política voltada para a construção de uma nação menos desigual, e que possibilite à sua população condições de se inserirem ativamente do meio social em que vivem, exercendo de forma plena seus direitos e deveres. Ou seja, as políticas macroeconômicas devem proporcionar à população as condições e a possibilidade de participar efetivamente da construção da nação.

\section{REFERÊNCIAS}

AGÉNOR, P. R. Business cycles, economic crises, and the poor: testing for asymmetric effects. Washington, D.C: World Bank, 2001

AGÉNOR, P. R. Macroeconomic adjustment and the poor: analytical issues and cross-country evidence. Washington, DC: World Bank, 2002. (World Bank policy research working paper, 2788)

AGÉNOR, Pierre-Richard. The Macroeconomics of Poverty Reduction. The Manchester School Vol. 73, No. 4, Special Issue. P. 369-434, 2005

AGHION, P.; BOLTON, P. A theory of trickle-down growth and development. Review of Economic Studies, Oxford, v. 64, n. 2, p. 51-172, Apr. 1997.

AMADEO, E. e NERI, M. Macroeconomic policy and poverty in Brazil. Rio de Janeiro: FGV/EPGE, 2000. Ensaio. econômicos FGV/EPGE, v n.373.

ARESTIS, P. Financial liberalization and poverty: channels of influence. Cambridge: University of Cambridge, Department of Land Economy, 2004.

ARESTIS, P. e SAWYER, M. Reinventing Fiscal Policy. The Levy Economics Institute of Board College. Working Paper No381, may 2003.

ARESTIS P. e SAWYER, M. The Case for Fiscal Policy. The Levy Economics Institute of Board College. Working Paper N ${ }^{\circ} 382$, may 2003.

ARESTIS. P. e SAWYER, M. On the Effectiveness of Monetary Policy and Fiscal Policy. The Levy Economics Institute of Board College. Working Paper N³69, 2003.

ARESTIS, P., NISSANKE, M. e STEIN, H. Finance and Development: Institutional and Policy Alternatives to Financial Liberalization Theory. Levy Economics Institute Working Paper No. 377. Abril. 2003.
BARRO R \& GORDON, D Rules, Discretion and Reputation in a Model of Monetary Policy. Journal of Monetary Economics, 12: 101-121, 1983.

BARROS, R. P. et al. Poverty, inequality and macroeconomic instability. Texto para discussão IPE $A n^{\circ}$. 750. Rio de Janeiro: IPEA, 2000.

BARROS, R. P. et. al. Determinantes imediatos da queda da desigualdade de renda brasileira. Texto para discussão IPE $A n^{\circ}$. 1253. Rio de Janeiro: IPEA, 2007.

BARROS, R. P. et al. A importância da queda recente da desigualdade na redução da pobreza. Texto para discussão IPE $A n^{\circ}$. 1256. Rio de Janeiro: IPEA, 2007b.

BARROS, R. P.; MENDONÇA, R. O impacto do crescimento econômico e de reduções no grau de desigualdade sobre a pobreza. Texto para discussão IPE $A n^{\circ}$ 528. Rio de Janeiro: IPEA, 1997.

BAUMANN, R. O Brasil dos anos 1990: uma economia em transição. In: BAUMANN, R (Org.) Brasil: uma década em transição. Rio de Janeiro: Campus, 2000.

BLANK, R. M. e BLINDER, A. S. Macroeconomics, Income Distribution and Poverty. NBER Working Paper Series n. $1567,1985$.

BLANK, R.; CARD, D. Poverty, income distribution and growth: are they still connected? Brookings Papers on Economic Activity, Washington, n. 2, p. 285-339, 1993.

BOURGUIGNON, F. The poverty-growth-inequalit triangle. Indian Council for Research on International Economic Relations. 2004. Disponível em http: / / siteresources.worldbank.org/INTPGI/ Resources/3426741206111890151/15185_ICRIER_paperfinal.pdf.

BRESSER-PEREIRA, L. C. Reformas Econômicas em tempos anormais. Revista da USP. N. 17, pp. 114-121, Março, 1993. 
BRESSER-PEREIRA, L. C.; NAKANO, Y. Uma estratégia de desenvolvimento com estabilidade. Revista de Economia Politica, São Paulo, v. 22, n. 3, p. 146 - 180, jul./set. 2002

CARDOSO Jr, J. C.; JACCOUD, L. Políticas sociais no Brasil: organizaç̃̃o, abrangência e tensões da ação estatal. In: JACCOUD, L. (Org.). Questão social e politicas sociais no Brasil contemporâneo. Brasília: IPEA, 2005. cap. 5, p. $181-260$.

CARVALHO, F. C. Políticas Econômicas para Economias Monetárias. In: LIMA, G. T., SICSU, J., e PAULA, L. F. (Org.) Macroeconomia Moderna: Keynes e a Economia Contemporânea. Rio de Janeiro: Editora Campus, 1999.

CARVAlHO, F. J. C. A Influência do FMI na Escolha de Políticas Macroeconômicas em uma Economia Emergente: o caso do Brasil. In: Agenda Brasil: Políticas Econômicas para o crescimento com estabilidade de precos. SICSÚ, J.; OREIRO, J. L., PAULA, L. F. (Org). Barueri, SP. Editora Manole, Fundação Koonrad Adenauer, 2003.

CARVALHO, F. J. C. Equilíbrio fiscal e política econômica keynesiana. Análise Econômica (UFRGS), v. 26, p. 7-25, 2008.

CASTRO, J. A.; CARDOSO JR, J. C. Políticas sociais no Brasil: gasto social do Governo Federal de 1988 a 2002. In: JACCOUD, L. (Org.). Ouestão social e políticas sociais no Brasil contemporâneo. Brasília: IPEA, 2005. cap. 6, p. $261-318$.

CASTRO, J. A.; RIBEIRO, J. A.; CHAVES, J. V.; DUARTE, B. C.; SIMÕES, H. B. Gasto social e politica macroeconômica: trajetórias e tensões no periodo 1995-2005. Brasília, IPEA, Jan. 2008. (Texto para discussão IPEA, n., 1324).

CEPAL. Crescer com Estabilidade: O Financiamento do Desenvolvimento no Novo Contexto Internacional. Rio de Janeiro: Editora Campus, 2002

CUTLER, D.; KATZ, L. Macroeconomic performance and the disadvantaged. Brookings Papers on Economic Activity, Washington, v. 22, n. 2, p. 285 - 339, 1993.

DOLLAR, D.; KRAAY, A. Growth is good for the poor. Journal of Economic Growth, Norwell, MA, v. 7, n. 3, p. 195 $225,2002$.

DOMAR, E. D. The 'Burden of the Debt' and the National Income. American Economic Review vol. 34. n²4, dez. 1944.

DRAIBE, S. M. A política social do governo FHC e o sistema de proteção social. Revista Tempo Social, São Paulo, v. 15 , n. 2 , nov. 2003.

EPSTEIN, G.; GRABEL, I. Financial policy. Brasilia: International Poverty Centre, 2007. (Training module, n. 3).

FERREIRA, F.H.G.; PRENNUSHI, G.; RAVALLION, M. Protecting the poor from macroeconomic shocks: an agenda for action in a crisis and beyond. World Bank policy research. working paper, n.2160. Policy Research, Washington, DC: World Bank, 2000.

IPEA. Sobre a recente queda da desigualdade no Brasil. Brasília, 2006. (Nota Técnica n. 9).

JACCOUD, L. Pobres, pobreza e cidadania: os desafios recentes da proteção social. Texto para discussão IPE $A, n$. 1324. Rio de Janeiro: IPEA, 2009.

KYDLAND, F. \& PRESCOTT, E. Rules Rather than Discretion: The Inconsistence of Optimal Plans. The Journal of Political Economy, Volume 85, Issue 3, June 1977, 473-92.

LERNER, A. Functional Finance and the Federal Debt. Social Research vol.10, pp. 38-51. 1943.

LEVACIC, R. e REBMANN, A. Macroeconomics: an introduction to Keynesian-neoclassical controversies. Palgrave Macmillan, 1982.

LUSTIG, N. Crises and the poor: socially responsible macroeconomics. Washington, D. C., Inter-American Development Bank, 2000.

MICHEL, R. Distribuição de Renda e Pobreza no Brasil: uma proposta de agenda. In: SICSÚ, J.; OREIRO, J. L., PAULA, L. F. (Org). Agenda Brasil: Politicas Econômicas para o crescimento com estabilidade de precos. Barueri: Editora Manole, 2003.

OCAMPO, J. A. Rethinking the Development Agenda. Cambridge Journal of Economics. May, 26:3. pp. 393-407. 2002.

OCAMPO, J. A. Beyond the Washington Consensus: an ECLAC perspective. CEPAL Review, No. 66 (LC/G.2049-P), Santiago, Chile, December. 1998.

OCAMPO, J. A. Latin America's Growth and Equity Frustrations during Structural Reforms. The Journal of Economic Perspectives, Vol. 18, No. 2, pp. 67-88, Spring, 2004.

OREIRO, J. L., SICSÚ, J., PAULA, L. F. Controle da Dívida Pública e Política Fiscal: uma alternativa para um crescimento auto-sustentado da economia brasileira. In SICSÚ, J.; OREIRO, J. L., PAULA, L. F. (Org). Agenda Brasil: Politicas Econômicas para o crescimento com estabilidade de preços. Barueri: Editora Manole, 2003.

PELIANO, A.M. Desafios e Perspectivas da Política Social. Texto para discussão IPE $A, n^{\circ}$. 1248. Brasília: IPEA, 2006.

REZENDE, F.; LIMA, E. C. P.; CÂNDIDO Jr., J. O. Finanças públicas. São Paulo: Atlas, 2001.

RAVALLION, M.; CHEN, S. What can new survey data tell us about recent changes in distribution and poverty? Polic research working paper, n.1694. Washington DC. World Bank, 1996.

ROCHA, S. Pobreza e desigualdade no Brasil: o esgotamento dos efeitos distributivos do Plano Real. Texto para discussão IPE $A, n$. 721. Rio de Janeiro: IPEA, 2000.

SAAD FILHO, A. Monetary policy. International Poverty Centre, Brasília, 2007. (Training module, n. 2)

SICSU, J. Emprego, Juros e Câmbio: Finanças Globais e Desemprego. Rio de Janeiro: Editora Elsevier, 2007.

SICSÚ, J. Teoria e Evidências do Regime de Metas Inflacionárias. Revista de Economia Política, São Paulo, v. 22, n. 1, p. 23-33, 2002.

SICSÚ, J.; PAULA, L. F.; MICHEL, R. Por que novodesenvolvimentismo? Revista de Economia Política, vol. 27 , n ${ }^{\circ} 4$ (108), pp. 507-524 outubro-dezembro/2007.

SICSÚ, J. Planejamento Estratégico do Desenvolvimento e as Políticas Macroeconômicas. Texto para discussão IPE A, n.1346. Brasília: IPEA, 2008

SOARES, F. V. et. al. Programas de transferência de renda no Brasil: impactos sobre a desigualdade. Texto para discussão IPEA, n.1228. Rio de Janeiro: IPEA, 2006.

STALLINGS, B; PERES, W. Crescimento, emprego e equidade: impacto das reformas econômicas na América Latina e Caribe. Rio de Janeiro: Editora Campus, 2002

TAYLOR, J. B. Discretion versus Policy Rules in Practice. Carnegie-Rochester Conference Series on Public Policy. Vol.39, pp. 195-214.1993.

OCAMPO, J. A., TAYLOR, L. Trade liberalization in developing economies: modest benefits but problems with productivity growth, macro prices, and income distribution. Working Paper n. 8, CEPA, New School, Nova York, 1998.

WEEKS, J.; PATEL, S. Fiscal policy. International Poverty Centre, Brasília, 2007. (Training module, n. 1). 


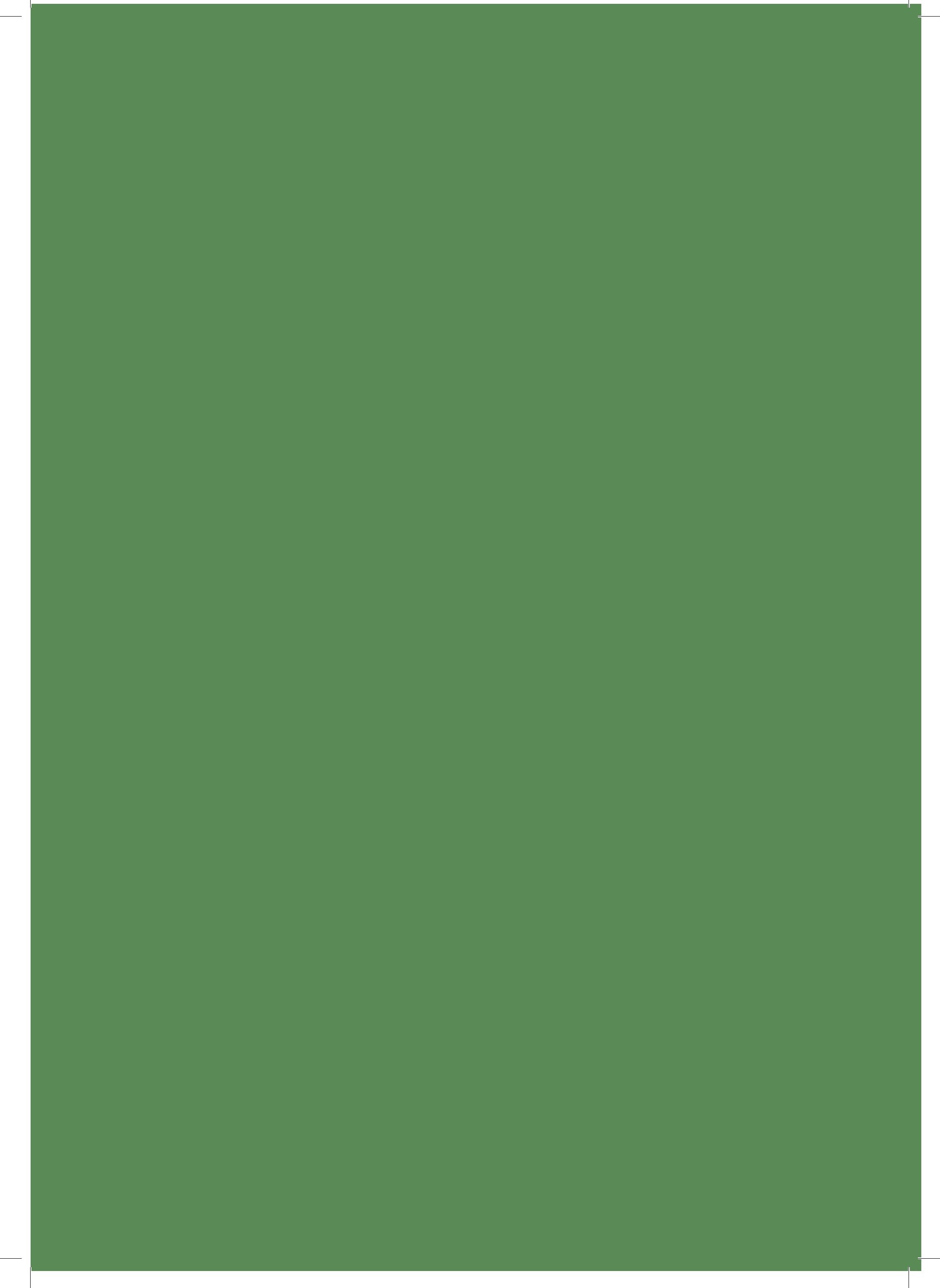

